\title{
PATTERN OF ACUTE PANCREATITIS: THE LIAQUAT UNIVERSITY HOSPITAL EXPERIENCE
}

\author{
Javed Naeem Qureshi, Abdul Sattar Memon, Saeeda Memon and Adeel Hamad Memon
}

\begin{abstract}
OBJECTIVES: To determine the aetiological factors, presentation and management of acute pancreatitis and to assess the outcome of different forms of management in our set up. DESIGN: A case series.

SETTING: Liaquat University Hospital, Jamshoro/Hyderabad - Sindh from January 2002 to December 2004.

METHOD: The data of 45 consecutive patients admitted with acute pancreatitis was collected through a proforma and assessed with reference to aetiological factors, clinical presentation and management in each case.

RESULTS: Majority (60\%) of the patients belonged to $30-40$ years of age. Thirty-six (80\%) patients presented in emergency. The most common aetiological factor for acute pancreatitis was gallstones and the pain, nausea and vomiting were the main symptoms. Serum amylase ( $>3 x$ normal) was seen in $\mathbf{3 6}(\mathbf{8 0} \%)$ patients. Prediction of severity was identified through Ranson score. It was $<3$ in $27(60 \%), 3$ in $13(28.9 \%)$ and 4 in $5(11.1 \%)$ patients. The mortality was $13.33 \%$ but the morbidity remained high with the sequelae of resolution in $>50 \%$ cases.

CONCLUSION: Acute pancreatitis in our set up shows a lower frequency of this disease when compared to the world literature. However, when compared with aetiology and presentation, the pattern remains the same. Meanwhile, due to adoptation of Western way of life, the incidence seems to be increasing. Due to patient's delayed arrival, the diagnosis depending upon the level of serum amylase seems to be misleading.
\end{abstract}

KEY WORDS: Pancreatitis, Acute. Management. Risk Factors.

\section{INTRODUCTION}

Acute pancreatitis is an autodigestive process; activation of pancreatic enzymes leading to pancreatic damage with a local and systemic inflammatory response. There has been much confusion regarding definition and use of terms in acute pancreatitis. To resolve this dilemma, a group of international experts met in 1992 and agreed on a set of definitions for both mild and severe acute pancreatitis together with its complications. ${ }^{1}$ Mild acute pancreatitis is associated with minimal organ dysfunction and an uneventful recovery. It lacks the features of severe acute pancreatitis. However, severe acute pancreatitis is associated with organ failure and/or local complications such as necrosis, abscess, or pseudocyst. Annual incidence of acute pancreatits in United Kingdom varies between 30 and 50 cases per 100,000 population. Most cases are mild, but about a quarter of patients suffer a severe attack and about $25 \%$ of these die, giving an overall mortality between $5 \%$ and $10 \%{ }^{1,2}$ Common aetiological factors of acute pancreatitis include gallstones, alcohol and idiopathic. ${ }^{2}$ However, other associated factors are ischaemia, endoscopic retrograde cholangiopancrea- ticography (ERCP), pancreatic or ampullary malignancy, infection (cytomegalovirus and mumps), trauma including surgery, hyperlipidaemia, hypercalcaemia, anatomical abnormalities (pancreas divisum), drugs (steroids, thiazide diuretics, anticholinesterases), hereditary pancreatitis etc. In Western part of world, incidence of pancreatitis is high because of high incidence of gallstones and alcohol consumption. In younger age, this disease is related to alcohol while in old age with gallstones. This paper presents pattern of acute pancreatitis in our set up.

\section{PATIENTS AND METHODS}

This descriptive study was conducted from January 2002 to December 2004 at Liaquat University Hospital Hyderabad/Jamshoro. It included 45 cases of acute pancreatitis. Data of all the patients was collected through a proforma which contained variables for preoperative, operative and post-operative assessment of the cases. Data obtained and recorded included age, sex, clinical features, date of operation, date of discharge, type of operation performed, emergency or elective surgery, post-operative stay and postoperative complications. Pre-operative assessment 
included all baseline and relevant specific investigations like LFT, blood CP, serum amylase, serum proteins, serum calcium, serum glucose level, abdominal ultrasound, urea, electrolytes and the CT Scan. In order to assess the prediction of severity to identify those requiring intensive care support and specific therapies, Ranson's criteria were used. For management purpose, standard treatment regimens were used. Post-operatively, all the patients were kept nil orally till return of the bowel sounds.

\section{RESULTS}

Total 45 cases were included in this study. There were 30 males and 15 females. Age of the patients ranged from 30 to 60 years. Twenty-seven(60\%) patients were of 30 to 40 years age. Thirty-six(80\%) patients presented in emergency. Clinical presentation of the cases is given in Figure $\mathbf{I}$. The most common aetiological factor of acute pancreatitis was gallstones followed by idiopathic, trauma and alcohol (Figure II). The diagnosis of acute pancreatitis was based on clinical history and examination in association with a markedly elevated serum amylase ( $>3 \times$ normal), observed in 36 patients (80\%). The other patients were diagnosed by ultrasound and CT scanning due to delayed arrival. Prediction of severity was identified through Ranson scores. ${ }^{3}$ A number of clinico- biochemical scoring system (Ranson) measures eight parameters. It was $<3$ in $27(60 \%)$ cases, 3 in 13 (28.9\%) and 4 in 5(11.1\%) patients. All 45(100\%) patients at the time of admission were treated with I/V fluids and electrolytes, antibiotics ( $3^{\text {rd }}$ generation cephalosporin) and analgesics. Nasogastric tube was passed for those with nausea and vomiting to empty the stomach in 30(66.7\%) cases. Oxygen $\left(\mathrm{O}_{2}\right)$ therapy was given to $7(15.6 \%)$ patients with cyanosis. Only 4 (8.9\%) patients had arterial blood gases done and were treated at intensive care unit. Two (4.4\%) patients further required ventilation. Octeriotide infusion was given in severe form of acute pancreatitis, i.e. in $5(11.1 \%)$ cases in the dose of 100 $\mu \mathrm{g}$ after diluting with $0.9 \% \mathrm{NaCl}$. Proton pump inhibitors were also given in all patients to avoid stress ulceration in a dose of $20 \mathrm{mg} /$ day. Details of surgical interventions are presented in Table I. Ultrasound guided aspiration was carried out in $2(4.4 \%)$ cases followed by continuation of I/V antibiotics. Ten patients (22.2\%) with common bile duct stones underwent ERCP and they were referred and followed up with open cholecystectomy. Laparoscopic cholecystectomy was carried out in $2(4.4 \%)$ such cases. Pseudocyst was found in $10(22.2 \%)$ cases, which were treated by cystogastrostomy after a phase of 6 weeks to 3

FIGURE I: CLINICAL PRESENTATION OF PATIENTS ( $n=45)$

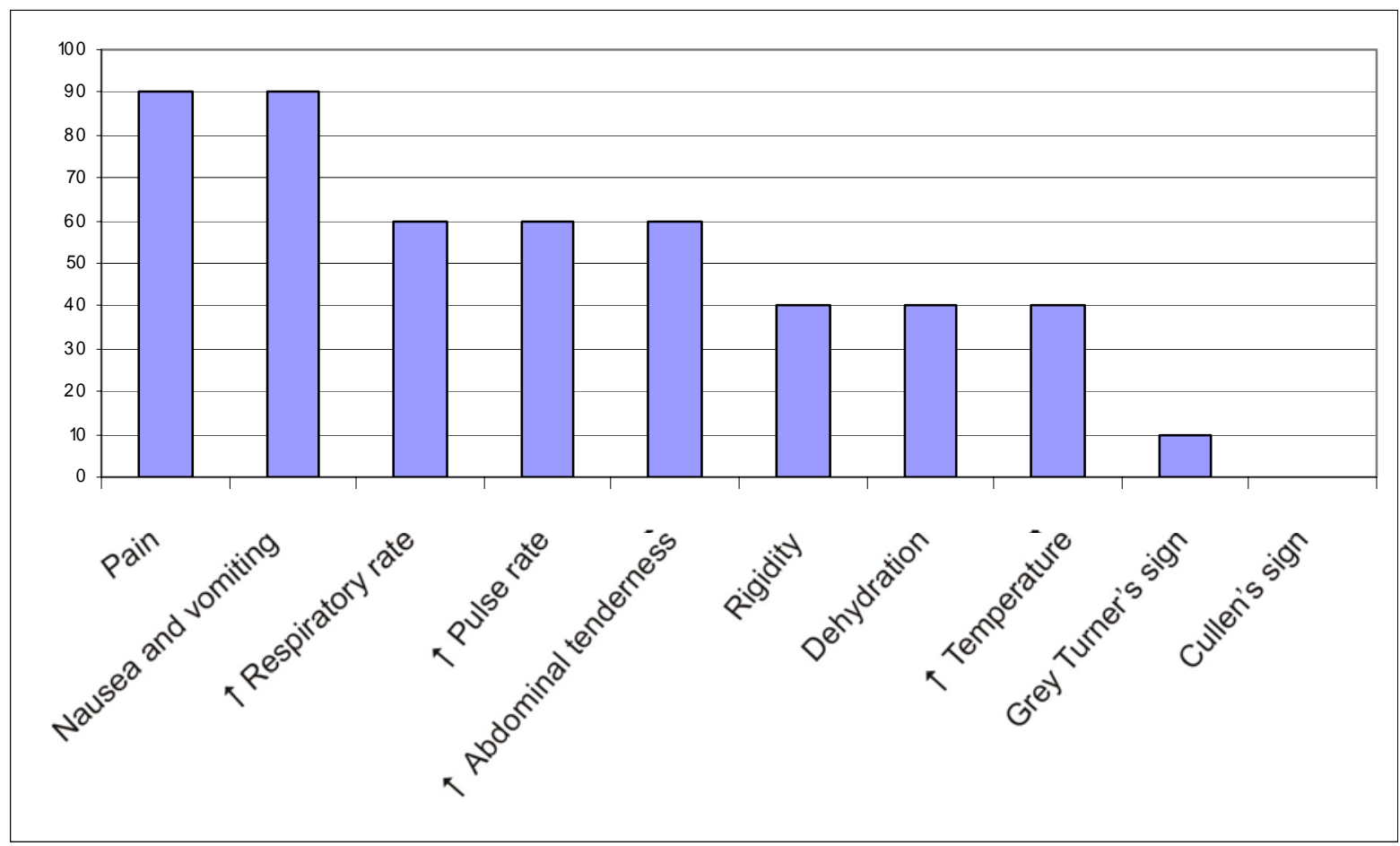


months duration. The mortality was $13.33 \%$ (6 patients) but the morbidity remained high with the sequelae of resolution in more than $50 \%$ and remaining to recurrent abdominal pain and pseudocyst (Table II).

FIGURE II:

\section{COMMON AETIOLOGICAL FACTORS $(n=45)$}

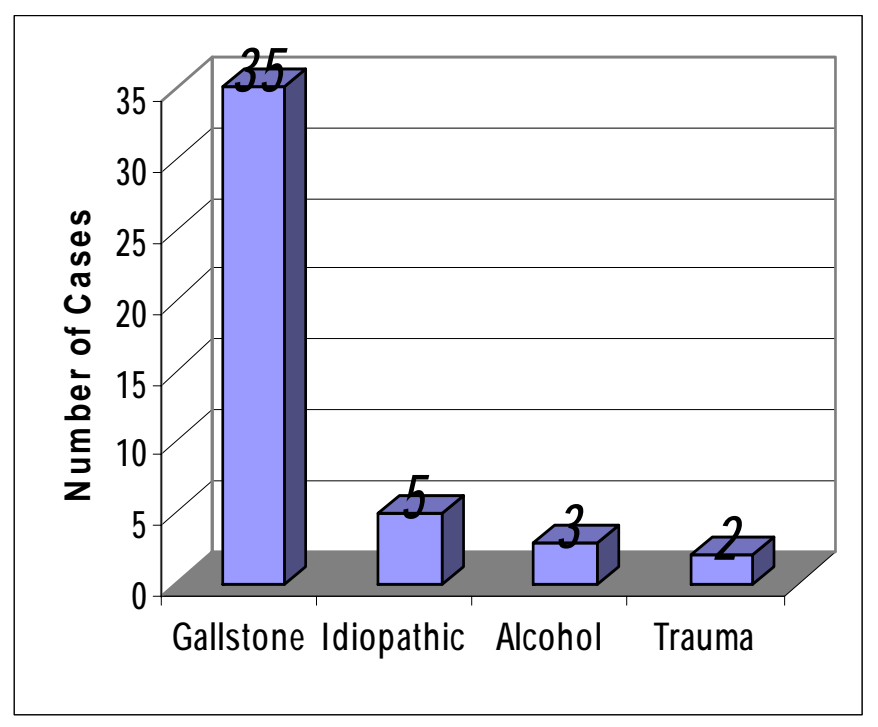

TABLE I:

\section{OPERATIVE PROCEDURES IN CASES OF ACUTE PANCREATITIS $(n=45)$}

\begin{tabular}{|l|c|c|}
\hline \multicolumn{1}{|c|}{ Procedure } & $\begin{array}{c}\text { Number of } \\
\text { Patients }\end{array}$ & $\begin{array}{c}\text { Percent- } \\
\text { age }\end{array}$ \\
\hline $\begin{array}{l}\text { Emergency laparotomy } \\
\text { for severe pain where di- } \\
\text { agnosis was difficult to rule } \\
\text { out. Peritonitis (2 cases) } \\
\text { and necrosectomy for pan- } \\
\text { creatic abscess (4 cases) }\end{array}$ & 6 & 13.3 \\
\hline $\begin{array}{l}\text { Elective cholecystectomy } \\
\text { (open) } \\
\text { for gallbladder stones }\end{array}$ & 33 & 73.3 \\
\hline $\begin{array}{l}\text { Elective laparoscopic } \\
\text { cholecystectomy }\end{array}$ & 2 & 4.4 \\
\hline $\begin{array}{l}\text { Pseudocyst cystogas- } \\
\text { trostomy }\end{array}$ & 10 & 22.2 \\
\hline ERCP & 2 & 4.4 \\
\hline $\begin{array}{l}\text { Ultrasound guided drain- } \\
\text { age of pancreatic } \\
\text { secretions }\end{array}$ & 2 & 4.4 \\
\hline
\end{tabular}

TABLE II:

SEQUELAE OF ACUTE PANCREATITIS

\begin{tabular}{|l|c|c|}
\hline & $\begin{array}{c}\text { Number of } \\
\text { Patients }\end{array}$ & Percentage \\
\hline Resolution & 23 & 51.1 \\
\hline $\begin{array}{l}\text { Recurrent } \\
\text { abdominal pain }\end{array}$ & 6 & 13.3 \\
\hline Pseudocyst & 10 & 22.2 \\
\hline $\begin{array}{l}\text { Peri-pancreatic fluid } \\
\text { collection }\end{array}$ & 2 & 4.4 \\
\hline Pancreatic abscess & 4 & 8.9 \\
\hline
\end{tabular}

\section{DISCUSSION}

Acute pancreatitis presents as a major surgical challenge and the nature and purpose of this research work was to assess the aetiological factors and mode of presentation of acute pancreatitis at two settings of emergency and elective admissions and different options of management and their outcomes. Among the aetiological factors; gallstones, idiopathic and the trauma were main factors, which is comparable with the findings of a study conducted by Slavin $\mathrm{J}^{1}$ Gallstone pancreatitis was more common in females than males, conversely, alcohol induced pancreatitis was more common in males, which also seconds the study of Slavin $\mathrm{J}^{1}$ It was interesting to note that in majority (68.89\%) of the patients with pancreatitis, history of smoking was positive but it is difficult to correlate with pancreatitis. ${ }^{4}$ Mild acute pancreatitis is associated with minimal organ dysfunction and an uneventful recovery. Severe acute pancreatitis is associated with organ failure and/or local complications. ${ }^{1,2}$ The mortality in patients with acute pancreatitis is associated with the number of failing organs and the severity and reversibility of the organ dysfunction. ${ }^{1,5}$ Early diagnosis and management is potentially curative. The incidence of disease has been increasing in our part of the world because of increasing trend of adopting Western lifestyle and consumption of alcohol. Hence, the prevalence has been reported high in urban populations as compared to rural one.

Patients with pancreatitis usually present with pain in upper abdomen radiating to back, and in our study too, pain was a pronounced feature that was not relieved by NSAIDs and required I/V narcotic 
analgesics. Elevated serum amylase, ultrasound and CT scanning were the main tools of diagnosis. Due to delay in arrival at the hospital, in $10(22.2 \%)$ cases, serum amylase was not helpful and it further delayed in confirming the diagnosis. Ultrasound was done in all the cases and found to be accurate in picking up gall stone related pancreatitis in $35(77.8 \%)$ cases. While, pancreatic oedema and peri-pancreatic fluid collection was picked up in $25(55.6 \%)$ cases. CT scanning is the imaging technique of choice and should be performed in all cases when clinical symptoms and laboratory findings are typical, however, the role of CT is to detect the complications. ${ }^{1,6,7}$ CT scanning was done in $10(22.2 \%)$ cases in this series where ultrasound was not helpful in diagnosis.

Acute necrotising pancreatitis is the most fulminating form of acute pancreatitis. As recently as 20 years ago, mortality from this disease process reached as high as $80 \%{ }^{1,8}$ However, prophylactic antibiotic therapy, surgical care and protocols for operative debridement have reduced this figure considerably. But, $80 \%$ of deaths from acute pancreatitis evolve from infective complications of pancreatic and peripancreatic necrosis. $^{8}$

The management of patients with acute pancreatitis is complicated by the ability to distinguish mild from severe disease during the early stages. ${ }^{9}$ In our setting, Ranson's bio-clinical criteria were used to predict the severity. This system requires 48-hours for accuracy in delivering severity. Although, the APACHE score can be calculated at admission and 24-hours, the accuracy of determining severity does not reach to significance until 48-hours. ${ }^{9}$ In this study, acute necrotising pancreatitis was the most fulminant form of acute pancreatitis, i.e. $4(8.9 \%)$ cases, which is comparable with the findings of an American study conducted by Hungness ES, et al. ${ }^{8}$ However, we could not distinguish between the sterile or infected form of necrotising pancreatitis, since WBC count was raised in all forms and pus culture was not sterile. An immediate laparotomy was carried out as opposed to West where patients with sterile necrosis undergo conservative treatment to early operative debridement. $^{7,8}$ In our setup, we carried out necrosectomy and peritoneal lavage and closed drainage in $4(8.9 \%)$ cases as we could not have the experience of laparostomy or closed continuous peritoneal lavage. ${ }^{10}$ We also could not have experience of managing pancreatic necrosis with $\mathrm{CT}$ guided tru-cut areas aspiration for gram stain and culture. ${ }^{2}$ However, in one setting, peri-pancreatic fluid collection in oedematous pancreatitis ultrasound guided aspiration was achieved and yielded good result of recovery in refractory attacks of pain in acute pancreatitis. Though, parenteral nutrition is preferred but enteral nutrition promises to attenuate inflammation and prevent sepsis. ${ }^{3}$ Ten (22.2\%) patients developed pseudocyst formation and presented after discharge over a period ranging from 2 months to 6 months. They required open cystogastrostomy and one was drained under ultrasound guidance with good result. Infectious complications are common diagnostic and therapeutic problems in severe acute pancreatitis and the use of prophylactic antibiotics in early management is advocated. ${ }^{11}$

All $35(77.8 \%)$ patients with gallstone underwent cholecystectomy including 2(4.4\%) with laparoscopy. All these patients had an uneventful recovery. In conclusion, due to increasing incidence of acute pancreatits, guidelines need to be implemented after all patients are classified on Ranson's scoring and referred to a specialised unit for managing pancreatitis or other complications requiring intensive care, radiological, endoscopic or surgical procedures in order to reduce the high mortality. ${ }^{12}$

\section{REFERENCES}

1. Slavin J. Acute pancreatitis. Surgery Int. 2002;59:227-30.

2. O'Reilly D, Kingsnorth A. Recent developments in acute pancreatitis. Int J Gastroenterol. 1999; 4 (3):16-8.

3. Russell RCG. The pancreas. In: Russell RCG, Williams NS, Bulstrode CJK (eds). Bailey \& Love's Short Practice of Surgery. $24^{\text {th }}$ edition. Arnold, London; 2004: Pp. 1114-32.

4. Berthier S, Michiels C, Sgro C, et al. Acute nonalcoholic non-biliary pancreatitis. Difficulties in diagnosis and possibility of nicotine toxicity. Presse Med. 2005; 34(11):795-6.

5. Mofidi R, Duff MD, Wigmore SJ, et al. The association between early systemic inflammatory response, severity of multi-organ dysfunction and death in acute pancreatitis. The Surgeon. 2005;3 (Supp3):S20.

6. Laurens B, Leroy C, Andre A, et al. Imaging of 
acute pancreatitis. J Radiol. 2005;86:733-46.

7. Ghidirim G, Gagauz I, Misin I, et al. Emphysematous necrotizing pancreatitis. Chirurgia (Bucur). 2005;100(3):293-6.

8. Hungness ES, Robb BW, Seeskin C, et al. Early debridement for necrotizing pancreatitis: is it worthwhile? J Am Coll Surg. 2002; 194(6):740-5.

9. Khan Z, Vlodov J, Horovitz J, et al. Urinary trypsinogen activation peptide is more accurate than hematocrit in determining severity in patients with acute pancreatitis: a prospective study. Am J
Gastroenterol. 2002; 97(8):1973-7.

10. Rau B, Bothe A, Beger HG. Surgical treatment of necrotizing pancreatitis by necrosectomy and closed lavage: changing patient characteristics and outcome in 19 years, single-center series. Surgery. 2005; 138(1):28-30.

11. Khan MN. Antibiotic prophylaxis in severe acute pancreatitis. Fauji Found Health J. 2000;1(2):2-6.

12. Taj A, Ghafoor MT, Amer W, et al. Mortality in patients with acute pancreatitis. Pak J Gastroenterol. 2002;16(2):35-8.

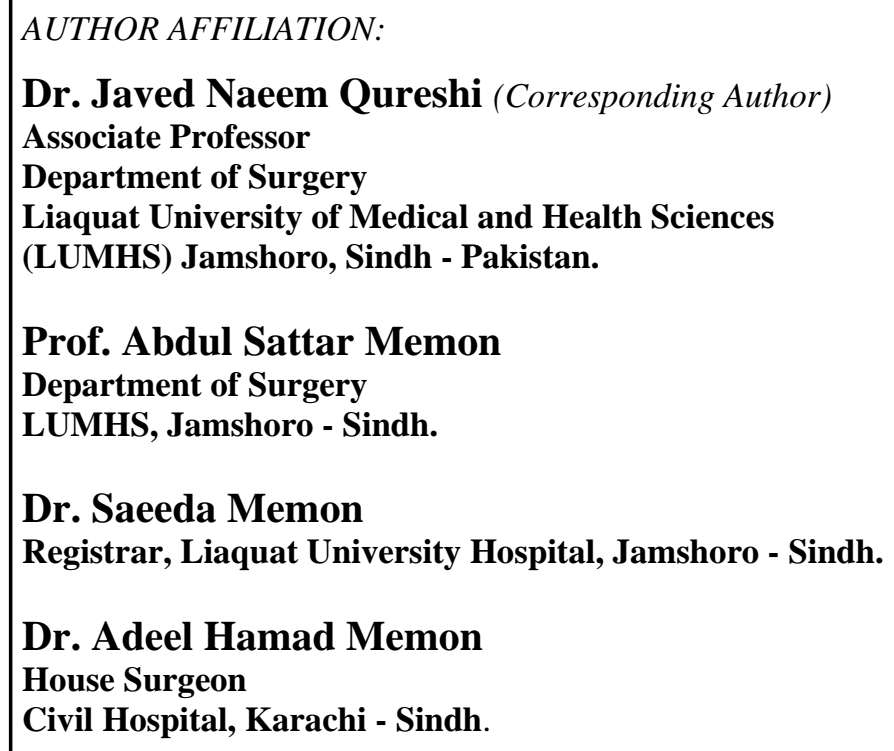

